\title{
An investigation into the detection of latent marks on the feathers and eggs of birds of prey
}

Helen McMorris, Kevin Farrugia, Dennis Gentles

This is the accepted manuscript (C) 2015, Elsevier

Licensed under the Creative Commons Attribution-NonCommercial-NoDerivatives

4.0 International http://creativecommons.org/licenses/by-nc-nd/4.0/

(cc) EY-NC-ND

The published article is available from doi:

http://dx.doi.org/10.1016/j.scijus.2014.12.004 


\title{
An investigation into the detection of latent marks on the feathers and eggs of birds of prey
}

\author{
Helen McMorris, Kevin Farrugia, Dennis Gentles * \\ School of Science, Engineering \& Technology, Division of Computing and Forensic \\ Sciences, Abertay University, Dundee, DD1 1HG, UK
}

\section{* Corresponding Author:}

School of Science, Engineering and Technology

Division of Computing and Forensic Sciences

Abertay University

Dundee DD1 1HG

United Kingdom

tel: $+44(0) 1382308110$

d.gentles@abertay.ac.uk 


\section{$\underline{\text { Abstract }}$}

There are numerous enhancement techniques (physical and chemical) which have been developed for the successful visualisation of latent fingermarks. Nonetheless, problems arise when latent fingermarks require enhancement on difficult surfaces such as human skin, food stuffs, fabric and animals. The ability to develop latent fingermarks on the surface of bird of prey feathers and that of their eggs was investigated. Red and green magnetic fluorescent powders proved to be most suitable on the surface of bird of prey feathers whereas black magnetic powder was the most suitable technique on the eggs. These powders produced the highest quality of visible ridge-detailed developments over a controlled period of time.

Keywords: fingermark, enhancement, magnetic powders, fluorescence, feathers, eggs 


\section{Introduction}

The Royal Society for the Protection of Birds (RSPB) reports that since 1989, in Scotland alone, there have been over 500 birds of prey killed by illegal poisoning with a further 340 confirmed as shot, trapped or with their nests destroyed [1]. Wildlife crime may be defined as, "the buying, selling, harming or disturbing of wild animals or plants that are protected by law," and at the beginning of 2012 the poisoning, trapping and illegal shooting of protected wildlife was thought to be more widespread than it has ever been in the past 50 years [2]. In the same year and region, there were 25 reported incidents of egg collecting and egg thefts, and seven reports of eggs being sold [1]. Illegal egg collection is now a well-equipped activity with the nest disturbers being in possession of all the necessary outdoor clothing and climbing gear needed to reach the more highly sought after eggs.

Fingermarks may be recovered from numerous crime scenes and can still provide a categorical conclusion rather than one based on probability for evidence such as DNA or fibre analysis and are now being researched as the main method by which this vital wildlife crime to suspect link can be forged [3]. Additionally, the Home Office Centre for Applied Science and Technology (CAST) reports that despite some public perceptions that fingermarks have mostly been superseded by DNA, fingermarks still account for appreciably more identifications overall and show no sign of being phased from use [4]. The surface onto which a fingermark has been deposited will ultimately determine the enhancement technique selected to develop that mark, in particular its porosity, however the condition and/or composition of the latent fingermark itself and the level of contamination present within the deposition, if any, are also contributing factors. Recent research endeavours in latent mark detection on difficult surfaces include human skins [5-7], food stuffs [8-10], fabric [11] and animals [12-14]. Cyanoacrylate fuming and powdering techniques have been reported as potential enhancement techniques for deer antlers, elephant tusks and live reptiles [12-14].

With the killing of wild animals equating to big business for poachers, wildlife DNA analysis is currently popular for the characterisation of different species [15-17], however the use of fingermark enhancement in the investigation of wildlife crime appears to be limited. The microscopic weave structure of a feather has been likened to that of fine weave fabrics such as nylon, upon which it is may be possible to develop grab marks using vacuum metal deposition and touch DNA profiling. The main aim of this study was to investigate a range of latent fingermark development techniques for the development of latent fingermarks on specific bird of prey feathers and eggs. 


\section{Materials and Methods}

\section{Sample preparation}

A total of six species of bird of prey feathers (kestrel, sparrowhawk, buzzard, red kite, golden eagle and white-tailed eagle) and seven species of bird of prey eggs (kestrel, sparrowhawk, golden eagle, goshawk, tawny owl, barn owl and long-eared owl) were examined (figure 1). The eagle feathers and eggs were provided by a local falconer whereas the rest of the feathers and eggs were provided by the Science and Advice for Scottish Agriculture (SASA) and a local museum. The feathers provided from SASA had been sampled from a vast range of frozen bird carcasses connected to cases of illegal poisoning which had been defrosted prior to sampling. The individual feathers were stored in breathable trays at room temperature, in normal lighting conditions and handled with gloves at all times to reduce the risk of infection from any tissue remaining on the quills of the feathers. The trays were lined with paper towels and covered with breathable brown paper. SASA also provided 2 complete buzzard wings which were placed in clear plastic bags and stored in a freezer until required. The eagle feathers provided by the falconer required cleaning and after advice from a taxidermist, an air compressor was used to gently blast the dirt and other contaminants off the surface whilst also ensuring the water-proofing ability of the feathers remained intact. The eggs were all gently bathed with a mild detergent and distilled water to remove any dirt and other contaminants that might be present before gently dried with cotton wool. The eggs were stored at room temperature in shallow cardboard boxes that were lined and covered with cotton wool.

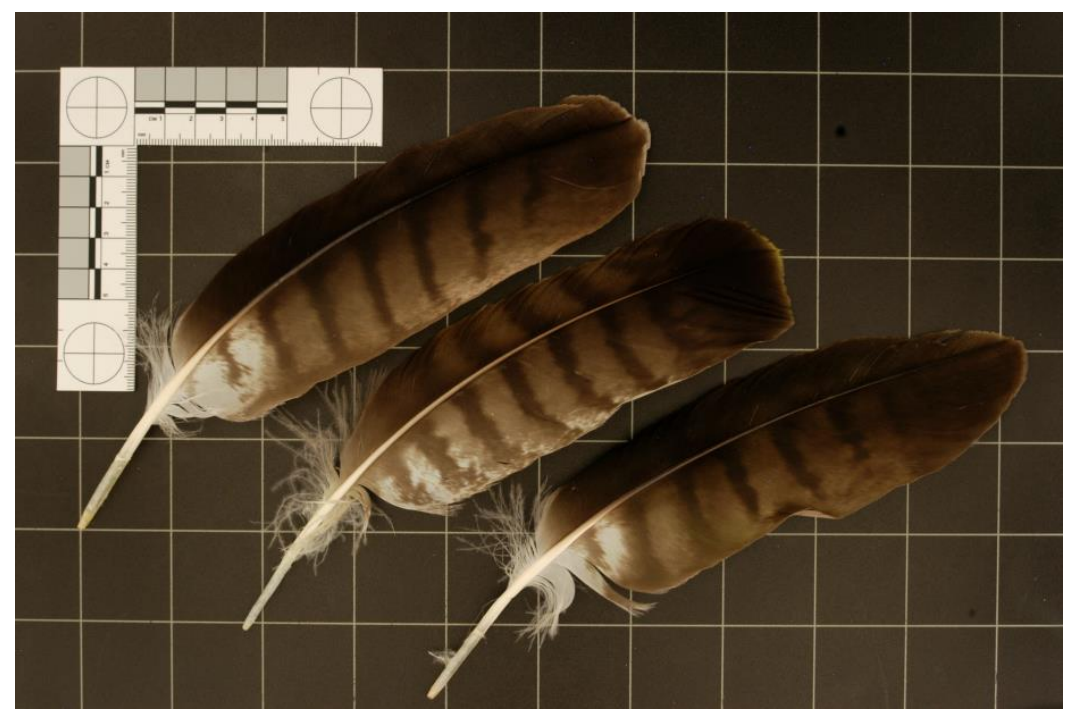

Figure 1 - Examples of buzzard feathers 


\section{Fingermark Deposition and Ageing}

The suitability of 11 fingermark donors for use in the investigation, in terms of whether they are good, medium or poor fingermark donor, was assessed by the enhancement of their fingermarks on a sheet of white, blank A4 paper using black magnetic powder. 5 donors ranging from good to poor donors and between the ages of 19-45 years old were selected and asked to refrain from washing their hands for at least 1 hour prior to depositing their fingermarks. Each donor was asked to rub their hands together and deposit a fingermark onto a designated area on the feather and egg surface. A diminishing series was not used in this study. Some of the eggs, such as the barn owl and sparrowhawk eggs were very small and did not allow for all 5 donors to deposit their fingermarks, therefore in some cases only 4 donors were used, and in others just 1 donor. Additionally, due to the supply of feathers, not all techniques and ageing periods could be assessed. Contact was made with the surface of the feathers and the eggs for approximately 2 seconds and an attempt was made to keep the contact pressure as constant as possible. Feathers and eggs from all species supplied for use in this investigation were prepared each week and developed over a 3 week period at intervals of 1 day, 3 days, 7 days, 14 days and 21 days after deposition. These time scales were repeated for all enhancement techniques under investigation.

\section{Fingermark Grading}

Following enhancement, all of the developed fingermarks were graded on a scale of 0-4, depending on the quality of ridge detail, if any, that was visible on the feathers and eggs. The grading system used was that recommended by CAST [18] as shown in table 1.

Table 1: Grading scheme for assessment of developed fingermark

\begin{tabular}{|c|c|}
\hline Grade & Level of Detail \\
\hline 0 & No evidence of print \\
\hline 1 & Some evidence of contact but no ridge detail present \\
\hline 2 & Less than $1 / 3$ of print showing clear ridge detail \\
\hline 3 & Between $1 / 3$ and $2 / 3$ of print showing clear ridge detail \\
\hline 4 & Over $2 / 3$ of print showing clear ridge detail \\
\hline
\end{tabular}




\section{Enhancement Techniques}

Each deposition was photographed before and after enhancement using a Nikon D5100 digital SLR camera with a $55 \mathrm{~mm}$ lens and a $60 \mathrm{~mm}$ micro Nikon lens. A Mason Vectron Quasar 2000/30 connected to an Integrated Rapid Imaging System (IRIS) was used for fluorescence examination. A control set of fingermarks was taken prior to each enhancement to ensure that each development technique was working effectively. Negative controls were also performed to ensure that the enhancement techniques were not reacting to any form of contamination. The enhancement techniques used in this study included the powders black magnetic powder, magneta flake powder, aluminium flake powder, magnetic bi-chromatic powder, red magnetic fluorescent powder, green magnetic fluorescent powder as well as cyanoacrylate fuming. All powders were obtained from CSI Equipment UK and applied via a magnetic wand brush except for aluminium flake powder which was applied using a Zephyr brush. Red magnetic fluorescent powder enhancement was observed by exciting with a violet/blue excitation source (band pass filter 400-469nm at $1 \%$ cut-on and cut-off points respectively) and viewed with a yellow long pass $476 \mathrm{~nm}$ filter (1\% cut-on point) whereas green magnetic fluorescent powder was observed by exciting with a blue/green light (band pass filter $468-526 \mathrm{~nm}$ at $1 \%$ cut-on and cut-off points respectively) and viewed with an orange long pass $529 \mathrm{~nm}$ filter (1\% cut-on point).

\section{Cyanoacrylate/BY40 [19]}

$2 \mathrm{~g}$ of cyanoacrylate (CSI equipment Ltd, UK) was placed into a new foil dish and positioned on a clean support ring on a heat source of about $120^{\circ} \mathrm{C}$ in the fuming chamber (Air Science CA305). The relative humidity level within the chamber was set at $80 \%$ with a running time of 45 minutes. A cycle time of 45 minutes ensured that $99.99 \%$ of the cyanoacrylate had evaporated as checked by the weight difference before and after the cycle. The fuming process was followed by immersion of the items under examination in a basic yellow 40 (BY40) solution for 1 minute followed by thorough rinsing under running tap water and left to dry at room temperature before fluorescence examination. BY40 dyeing on fumed items was performed the following day after fuming. BY40 (Sirchie) dye was prepared by dissolving $2 \mathrm{~g}$ in $1 \mathrm{~L}$ of ethanol (Fisher). Fluorescence was observed by exciting with a violet/blue excitation source (band pass filter 400-469nm at $1 \%$ cut-on and cut-off points respectively) and viewed with a yellow long pass $476 \mathrm{~nm}$ filter (1\% cut-on point). 


\section{Results and discussion}

This study sought to investigate a number of contributing factors that may affect the quality of enhancement of latent fingermarks. These include the composition of the marks at the time of deposit, the amount of sweat constituents present in the deposit, the condition and type of the receiving surface, the position of the deposited mark on the surface, environmental conditions and the length of time between the deposition of the mark and its enhancement [14]. The choice of enhancement method used can also contribute to the quality of latent fingermark obtained.

\section{Microscopic Examination}

The physical appearance of both the feathers and eggs were examined using a low power microscope. It is believed that feathers have similar physical properties to fabrics, in particular fine weave fabrics such as silk or nylon which have a high thread count per mm. The average thread count of the feathers was recorded at the tip, middle and base of the primary and secondary flight feathers. Primary flight feathers are the longest and narrowest feathers on the bird which can easily be rotated. They are very important for flight as they are the main source of thrust to move the bird forward through the air. Secondary feathers are shorter and broader with a blunt end. They remain close to the bird's body during flight and although they cannot rotate like primary feathers, they help to provide lift. They range in number from 4 for a hummingbird, to as many as 40 in some other species such as the albatross. The more 'threads' per mm, the tighter the weave and therefore the less surface distortion that would be experienced by any developed fingermarks. The sparrowhawk secondary flight feather measured 3 weaves per mm (figure 2), feathers of the red kite and buzzard measured $2-2 \frac{1}{2}$ weaves per $\mathrm{mm}$ and feathers of the white-tailed eagles had the thickest weave at $1-1 \frac{1}{2}$ per mm. These measurements appear to suggest that the bigger the bird of prey, the thicker the weave of their feathers. Regardless of the tightness of the weave, fabric has naturally occurring gaps between the warp and the weft thread as they inter-weave between each other, creating layering which can lead to possible surface distortion experienced by any developed fingermarks. The weave of a feather is planar and with a tighter weave there is reduced surface distortion. 


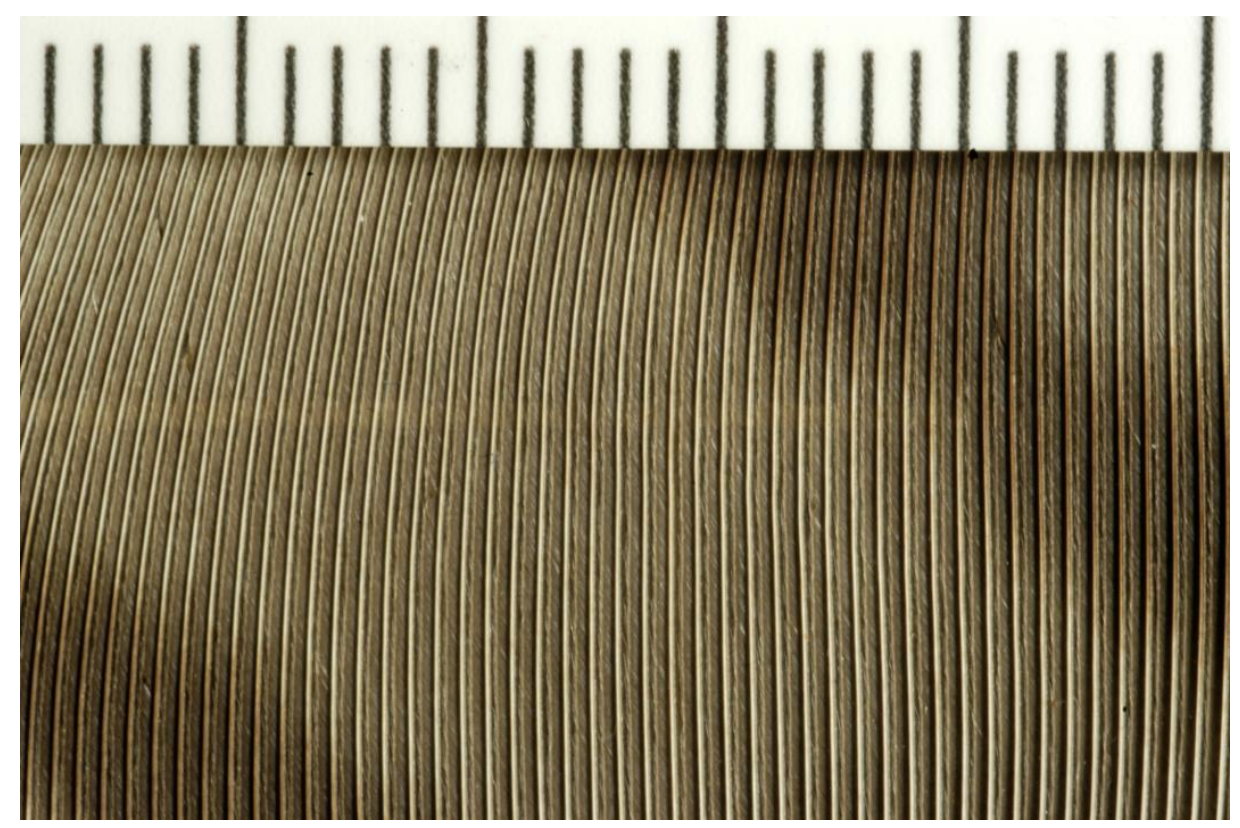

Figure 2 - Weave count of Sparrowhawk secondary flight feather (scale is in millimetres).

Although the eggs may appear to be smooth surfaced under the naked eye, microscopy showed an uneven and crater-like surface (figure 3). The visibly smooth surfaced goshawk egg appeared to glisten, with a lunar landscape appearance, covered in tiny crater like formations. The eagle eggs also revealed an uneven, crater-like surface; however, the surface was duller in comparison to the goshawk egg and did not glisten.

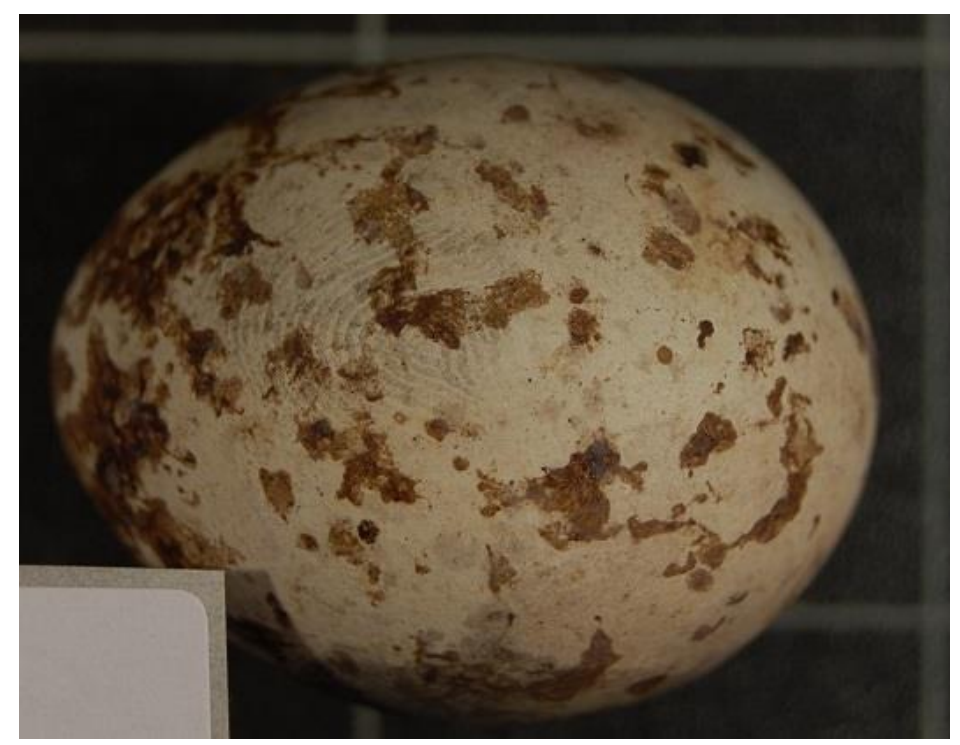

Figure 3 - Photography of a Sparrowhawk egg showing a developed fingermark with black magnetic powder. 


\section{Evaluation of Enhancement Techniques on Feathers}

Table 2 shows the number of positive marks (graded 1-4) developed using the three best enhancement techniques on bird of prey feathers. The magnetic fluorescent powders (red and green) scored highly with 62 positive enhancements from an original 70 deposits for red magnetic fluorescent powder and 59 from an original 70 marks for green magnetic fluorescent powder, equivalent to an overall percentage (\%) for positive mark development of $88.6 \%$ and $84.3 \%$ respectively. Overall, most of the marks graded positively were assigned 1 or 2 with a small number of marks graded 3 or 4 for the enhancement of marks on feathers used in this study.

The other powders and cyanoacrylate fuming also provided good overall development of latent fingermarks; however, the techniques were only tested on a smaller number of feathers due to the limited supply of feathers. Cyanoacrylate fuming/BY40 recorded $66.7 \%$ positive enhancements and black magnetic powder recorded $60 \%$ positive enhancements. Figure 4 demonstrates the cyanoacrylate polymerisation followed by BY40 staining on a sparrowhawk feather. The cyanoacrylate/BY40 process may be hindered by the water-proofing ability and hydrophobic nature of the feathers under study. The hydrophobicity of a surface is determined by the chemical composition of the surface (including the preening oils) and the surface texture [20]. Figure 5-7 represent some of the developed fingermarks on feathers of different birds of prey.

Table 2 - Number of positive marks developed on bird feathers

\begin{tabular}{|l|c|c|c|}
\hline & Magneta flake & $\begin{array}{c}\text { Red magnetic } \\
\text { Fluorescent }\end{array}$ & $\begin{array}{c}\text { Green magnetic } \\
\text { Fluorescent }\end{array}$ \\
\hline Grade 0 & 26 & 8 & 11 \\
\hline Grade 1 & 10 & 50 & 41 \\
\hline Grade 2 & 12 & 10 & 6 \\
\hline Grade 3 & 2 & 2 & 11 \\
\hline Grade 4 & 0 & 0 & $\mathbf{7 0}$ \\
\hline Total & $\mathbf{5 0}$ & $\mathbf{7 0}$ & 84 \\
\hline $\begin{array}{l}\text { Percentage of } \\
\text { positive marks (\%) }\end{array}$ & 48 & 89 & 6 \\
\hline
\end{tabular}




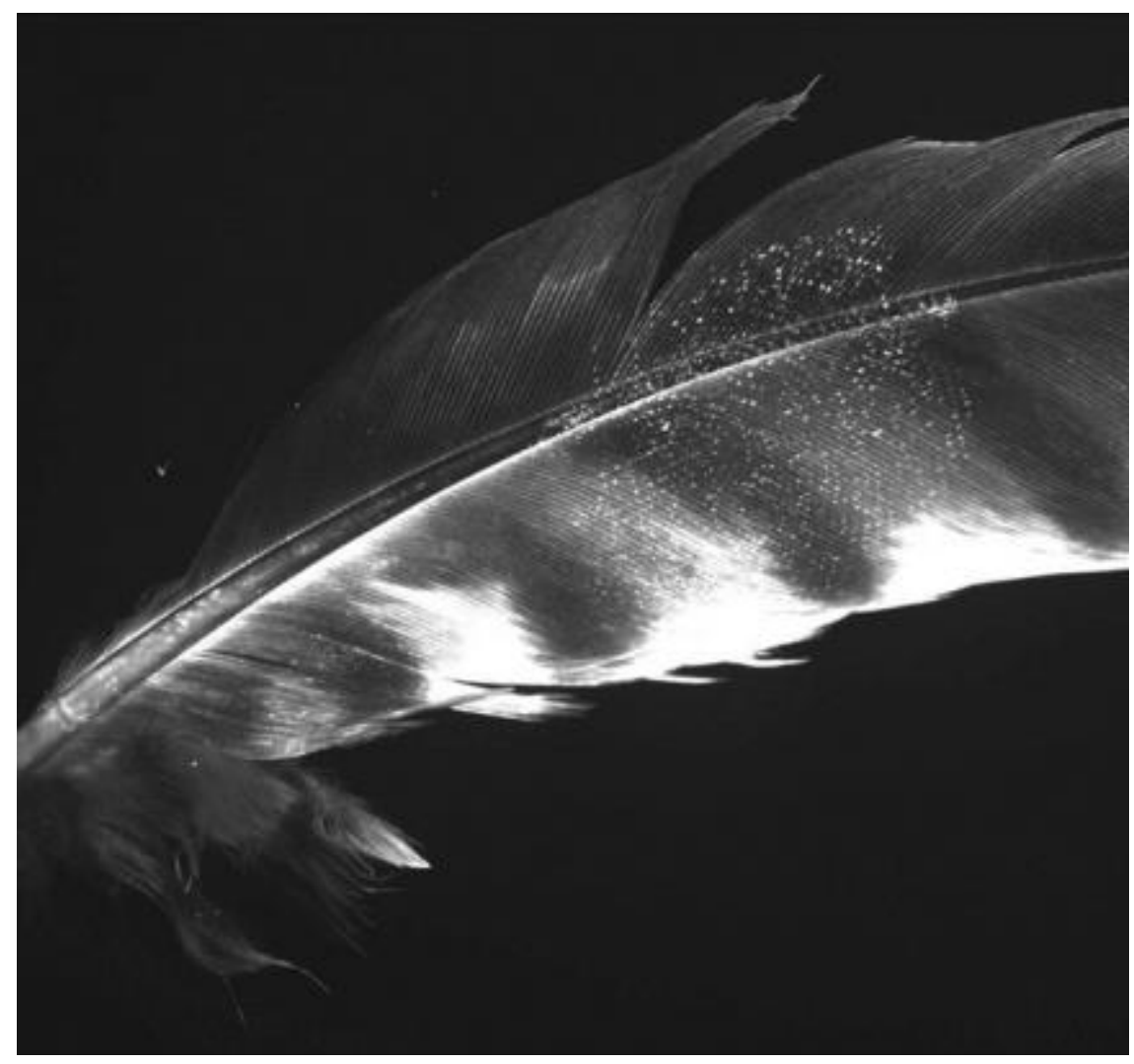

Figure 4 - A developed fingermark on a Sparrowhawk feather after treatment with cyanoacrylate fuming/BY40 and viewed under violet/blue light (yellow filter).

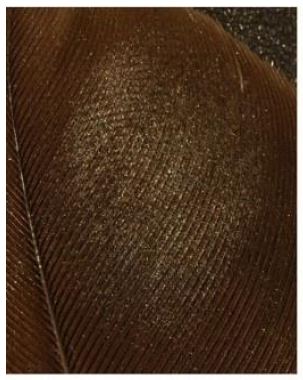

(a)

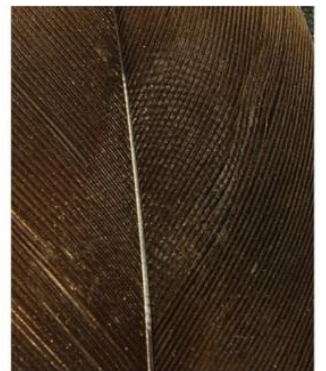

(b)

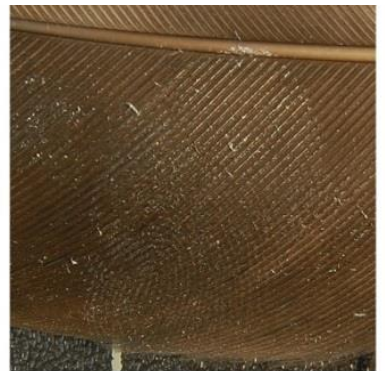

(c)

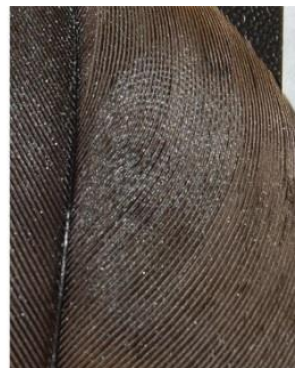

(d)

Figure 5 - Fingermarks developed with magneta flake powder on different feathers (from left to right): (a) buzzard aged 1 day; (b) red kite aged 3 days; (c) buzzard aged 7 days; (d) red kite aged 21 days. 


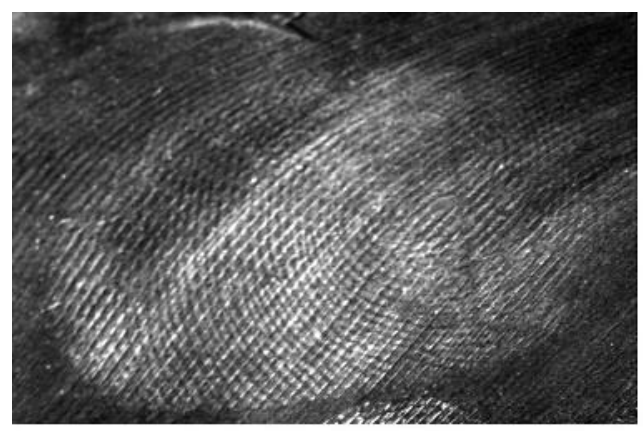

(a)

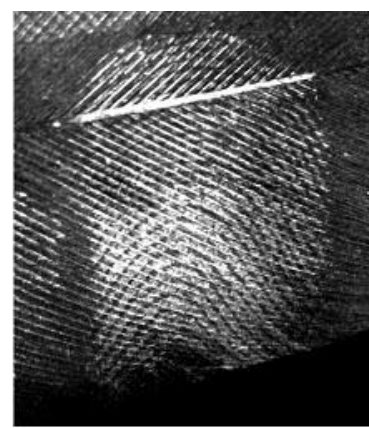

(b)

Figure 6 - Fingermarks developed with green fluorescent magnetic powder on buzzard feathers and aged for 3 days

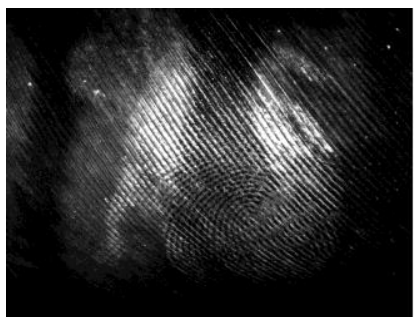

(a)

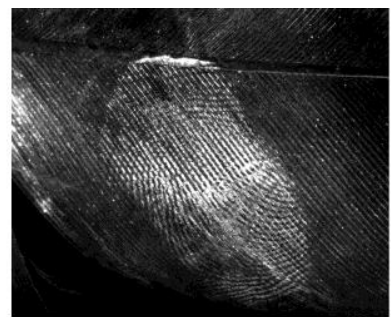

(b)

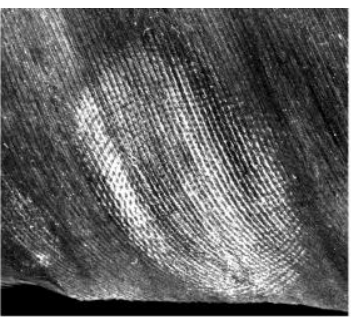

(c)

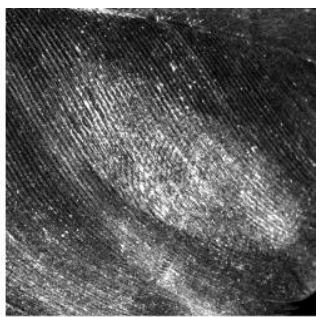

(d)

hh

Figure 7 - Fingermarks developed with green fluorescent magnetic powder on red kite feathers: (a) 1 day; (b) 3 days; (c) 14 days and (d) 21 days

Figure 8 compared the effectiveness of the three main enhancement techniques employed on feathers with the various ageing periods used in the study. There was an obvious depletion in the number of positive enhancements over the 21 day examination period when using all of the powders on the feathers, as would normally be expected as the constituents in a latent fingermark are gradually lost the longer they are exposed to environmental conditions. Red and green fluorescent magnetic powders performed consistently over the ageing period although there was a decrease in the number of positive enhancements at the 21 day period. Magneta flake powder decreased in the number of positive enhancements after 7 days and even more at 14 and 21 days. 


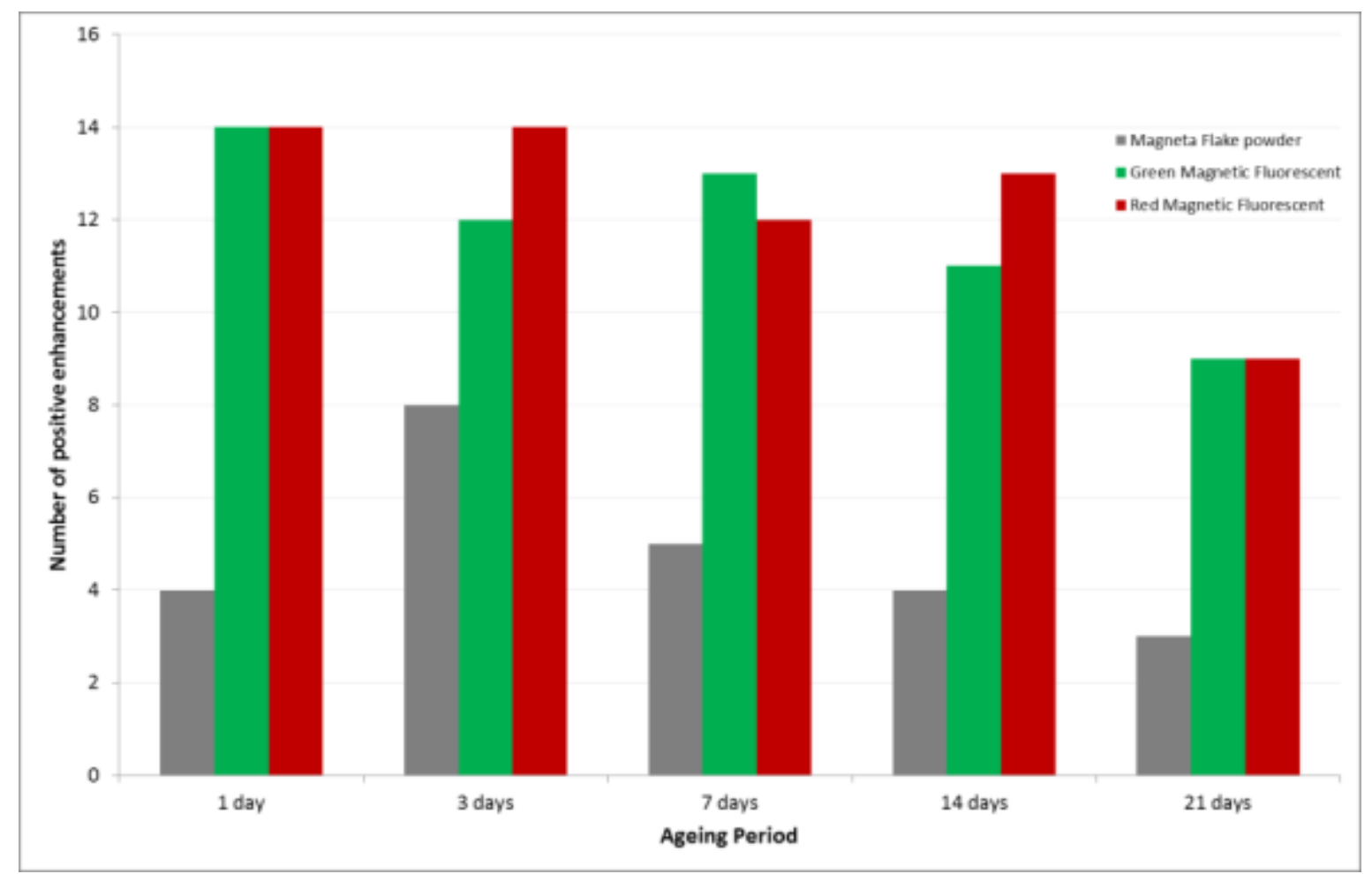

Figure 8 - Comparison of the number of positive enhancements observed on feathers by technique and ageing period

With the red and green magnetic fluorescent powders identified as the most promising techniques for the enhancement of latent fingermarks on bird feathers, these powders were used in an attempt to enhance latent fingermarks deposited onto two buzzard wings by two fingermark donors in a grab action in order to recreate how the wing of a dead bird would be handled. This was undertaken to determine if latent fingermarks could be obtained on a full wing to the same extent as they had been obtained on the individual feathers. The wings were developed 3 days after fingermark deposition. Using the red magnetic fluorescent powder on the right wing, a total of 3 fingermark shaped marks were visible, but with no identifiable ridge detail. The green magnetic fluorescent powder failed to successfully enhance any fingermarks on the left wing of the buzzard indicating that visible ridge detail was difficult to develop on the surface of the buzzard wings using both red and green magnetic fluorescent powders. Nonetheless, visible areas of contact on the wing surface were detected which could be swabbed for potential DNA evidence. A number of factors may have influenced this including the composition of the latent fingermark residue deposited and the grab action on the wing. It is also possible that the condition of the feather surface on the wings was different to the individual feathers due to the wings having been re-frozen and thawed under vacuum conditions prior to fingermark deposition. 
The buzzard and red kite feathers, which had a finer weave count, recorded the better quality ridge detail on the developed fingermarks. The eagle feathers, which had a thicker weave, recorded very little definable ridge detail, if any at all. This supported the hypothesis that the finer the weave of feathers, like that of fabric, the better the quality of fingermark that can be developed. With the red and green magnetic fluorescent powders identified as the most effective enhancement methods for use on bird feathers, it was interesting to note that the feather which appeared most suitable for enhancement with the red magnetic fluorescent powder was the buzzard feathers, recording 24 out of 25 positive enhancements (96\%) over the 21 day examination period, whilst the feathers most suitable for enhancement with the green magnetic fluorescent powder were the buzzard and eagle feathers, with each recording $100 \%$ positive enhancements over a 21 day examination period.

\section{Evaluation of Enhancement Techniques on Eggs}

Black magnetic powder proved to be the most effective enhancement technique for the development of latent fingermarks on the surface of bird of prey eggs as illustrated in table 3 , with a total of 46 out of 48 original deposits positively developed (graded 1-4) and including a high number of marks graded 3 or 4 . Other studies have reported the successful use of black magnetic powder for the development of latent marks on food items such as apples, tomatoes, onions and hens eggs [9-10].

Table 3 - Number of positive marks developed on bird eggs

\begin{tabular}{|l|c|c|c|c|}
\hline & $\begin{array}{c}\text { Black } \\
\text { magnetic }\end{array}$ & $\begin{array}{c}\text { Magnetic bi- } \\
\text { chromatic }\end{array}$ & $\begin{array}{c}\text { Magneta flake } \\
\text { powder }\end{array}$ & $\begin{array}{c}\text { Green magnetic } \\
\text { fluorescent }\end{array}$ \\
\hline Grade 0 & 2 & 7 & 2 & 2 \\
\hline Grade 1 & 6 & 9 & 1 & 1 \\
\hline Grade 2 & 8 & 13 & 2 & 1 \\
\hline Grade 3 & 16 & 5 & 0 & 3 \\
\hline Grade 4 & 16 & 2 & $\mathbf{5}$ & 2 \\
\hline Total & $\mathbf{4 8}$ & $\mathbf{3 6}$ & 60 & $\mathbf{9}$ \\
\hline $\begin{array}{l}\text { Percentage of } \\
\text { positive marks } \\
\text { (\%) }\end{array}$ & 96 & 81 & 0 & 78 \\
\hline
\end{tabular}


In general, feathers and eggs of birds of prey may be considered porous and non-porous respectively. Although non-porous enhancement techniques are suitable for egg shells, it is important to consider that the shells are actually porous with very small pores to allow the chick to breathe oxygen during development [21]. Black magnetic powder proved to be the most effective enhancement technique for use on the raptor eggs where $100 \%$ positive enhancements were recorded for goshawk, barn owl and long-eared owl eggs across all ageing periods. Figures 9-12 represent some of the developed fingermarks achieved at each of the time intervals using a selection of the enhancement techniques. Figure 13 illustrates the effectiveness of the two best enhancement techniques across the different ageing periods used in the study for eggs. The highest number of positive enhancements at each of the development time intervals was recorded with the black magnetic powder with $100 \%$ enhancement at 1 day, 7 days and 14 days after deposition of the fingermarks by the five donors.
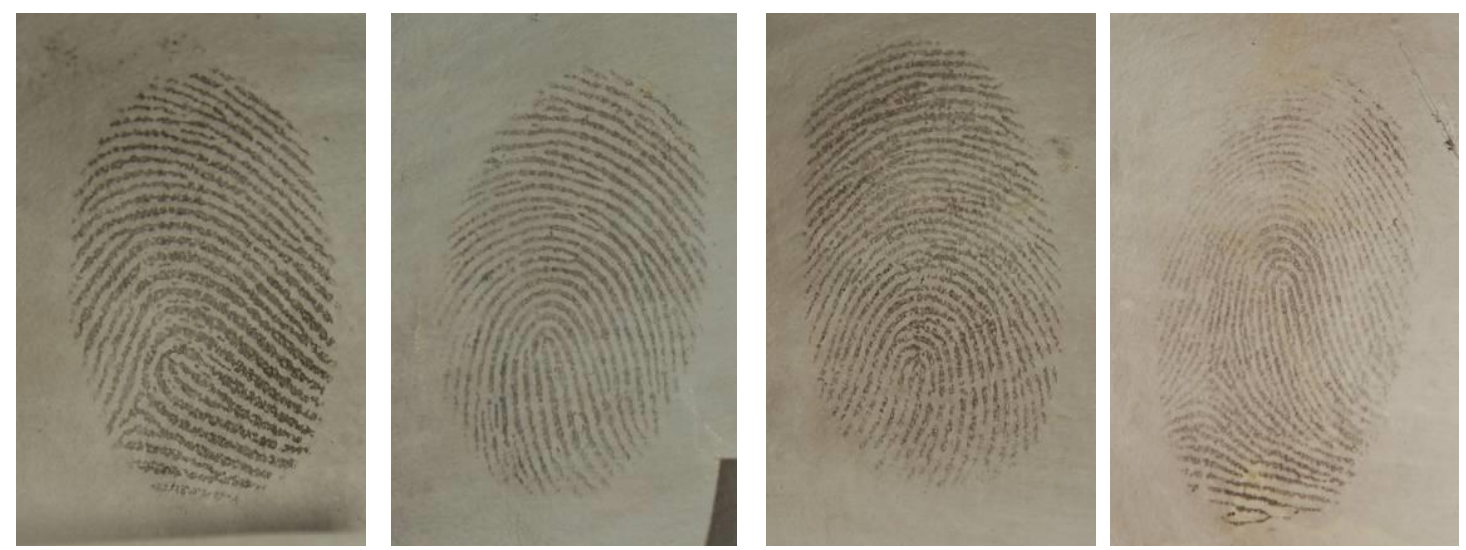

Figure 9 - Fingermarks developed with black magnetic powder on goshawk eggs after ageing: (a) 1 day; (b) 3 days; (c) 7 days; (d) 14 days
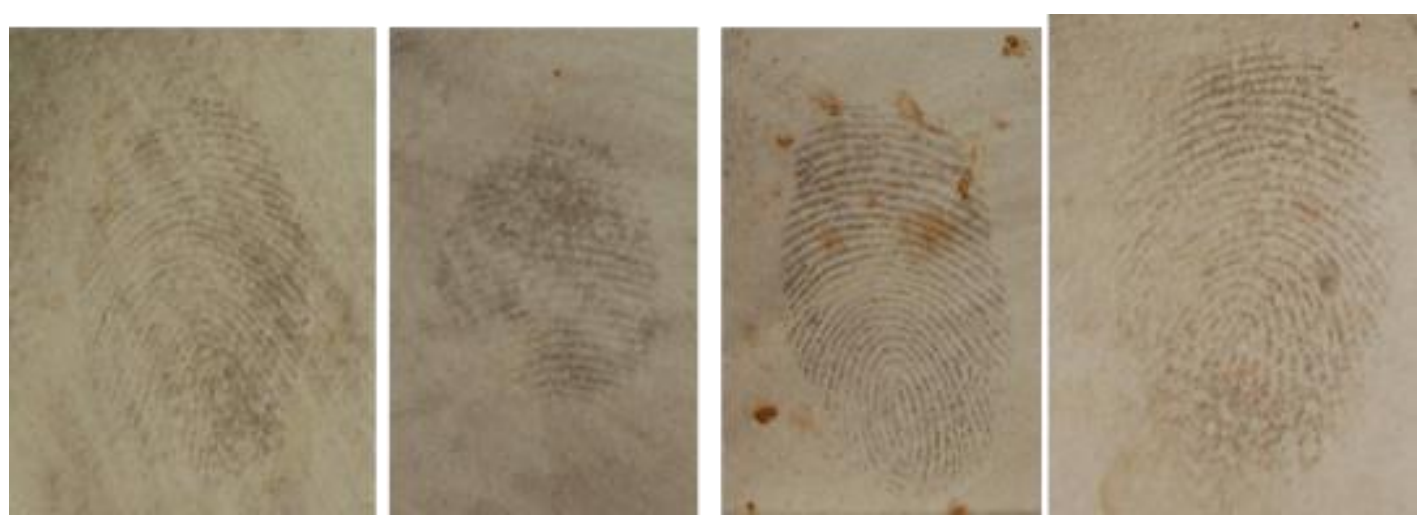

Figure 10 - Fingermarks developed with black magnetic powder on eagle eggs after ageing: (a) 1 day; (b) 3 days; (c) 7 days; (d) 14 days 

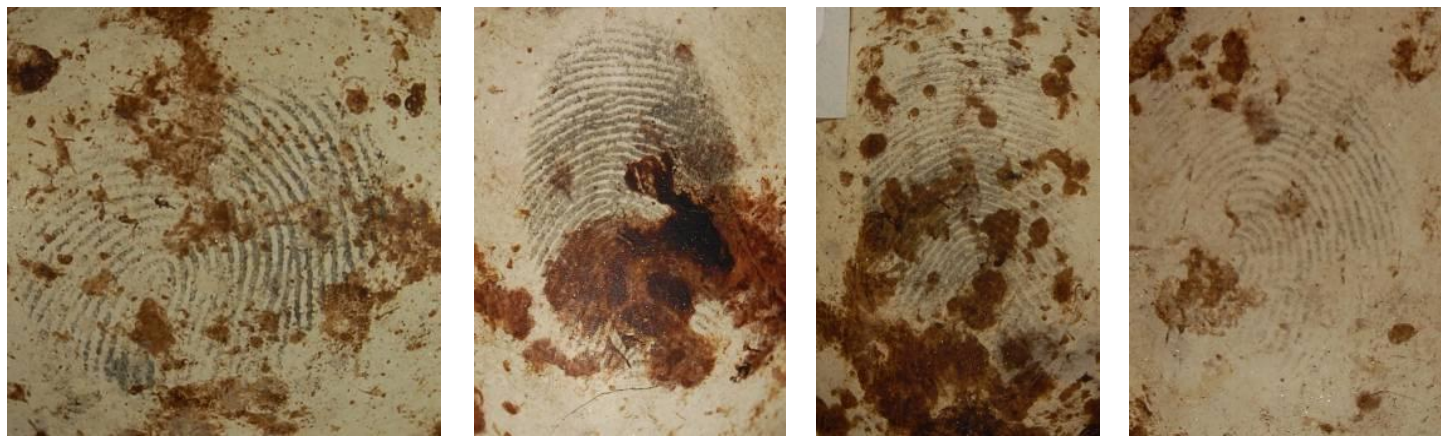

Figure 11 - Fingermarks developed with magnetic bi-chromatic powder on sparrowhawk eggs after ageing: (a) 1 day; (b) 3 days; (c) 7 days; (d) 14 days

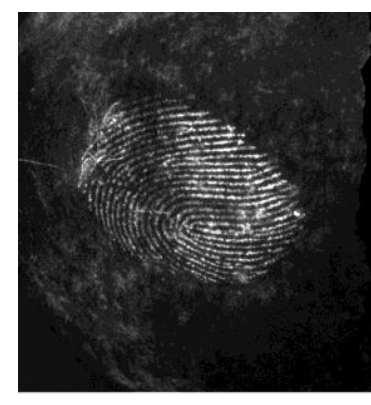

(a)

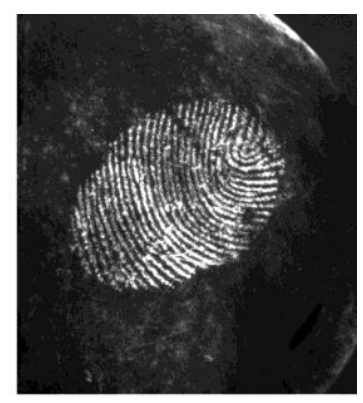

(b)

Figure 12 - Fingermarks developed with green magnetic fluorescent powder on tawny owl eggs after ageing 7 days

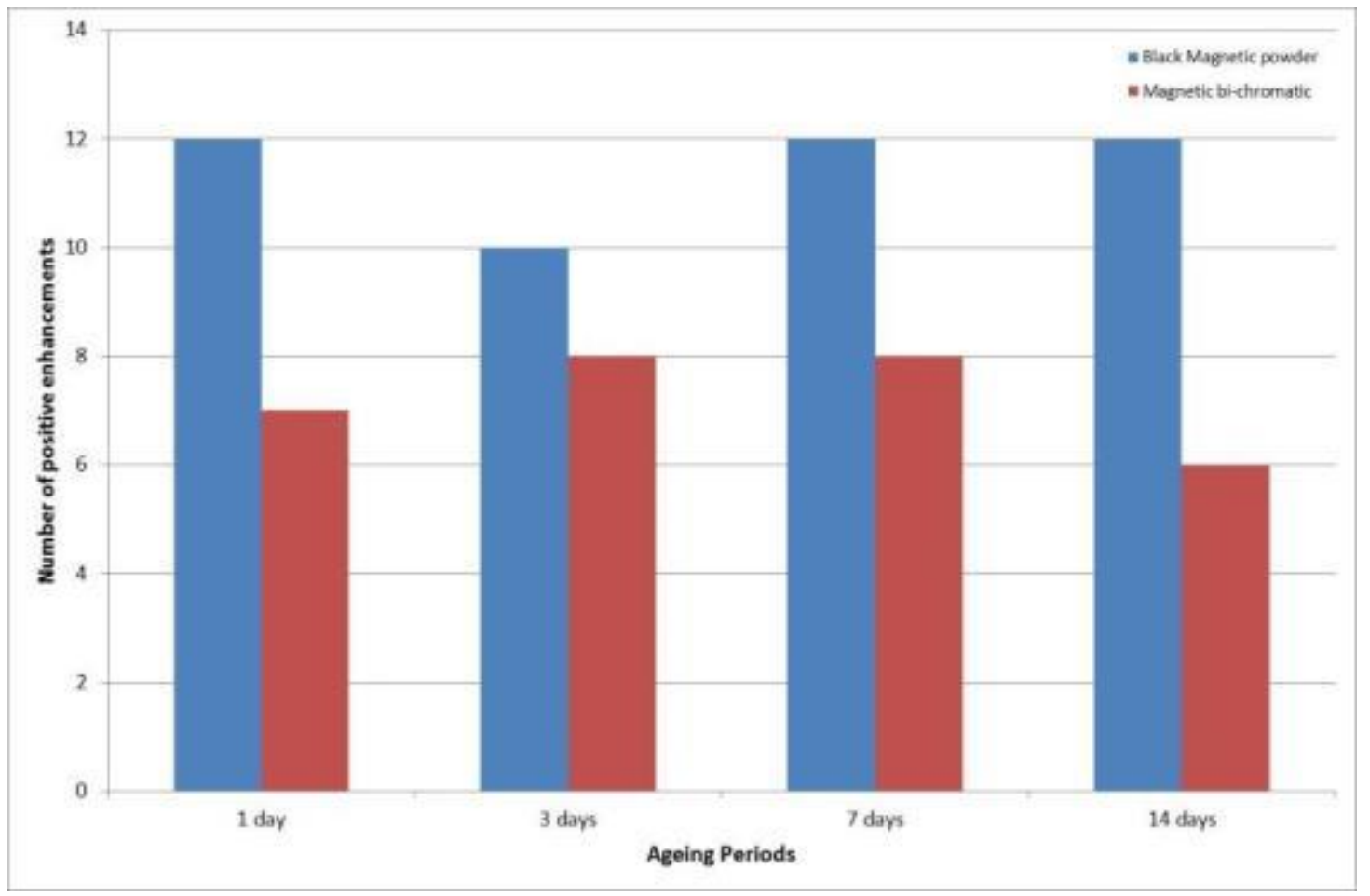

Figure 13 - Comparison of the number of positive enhancements observed on eggs by technique and ageing period 


\section{Conclusion}

This study found that the red magnetic fluorescent powder was overall the most suitable technique for the enhancement of latent fingermarks on bird feathers, achieving 88.6\% positive enhancements on three species of bird feather - buzzard, red kite and eagle. This was very closely followed by the green magnetic fluorescent powder which achieved $84.3 \%$ positive enhancements on the same three species of feathers. The least successful technique for the enhancement of latent fingermarks on bird feathers were white magnetic powder and aluminium powder. Previous studies had found black magnetic powder to be the most successful enhancement technique for latent fingermarks on food items including that of hen eggs, and it was also the most successful technique for the development of latent fingermarks on the surface of bird of prey eggs, achieving 95.8\% positive enhancements in total across 4 species of eggs. The least successful enhancement technique for use on the raptor eggs was aluminium powder. Buzzard and red kite feathers were found to be the most effective surface for the development of fingermarks in comparison to the eagle feathers but this may be as a result of the buzzard and red kite feathers having a finer weave. In relation to the eggs, the goshawk, barn owl and long-eared owl eggs were found to be the most effective species for the development of latent fingermarks.

Marks aged for 21 days were still enhanced effectively on the surface of the feathers and there was no discernible difference when compared to marks that had been aged for 1 day only. Although in many cases not enough ridge detail was developed on the enhanced fingermarks to make an identification, the touch marks may point to suitable areas for DNA analysis. Future work will include the continued study into the use of magnetic fluorescent powders for the development of latent fingermarks on bird feathers. Consideration will also be given to the possibility of obtaining a DNA sample from visible human touch marks. 


\section{References}

1. RSPB, The illegal killing of birds of prey in Scotland in 2012, 2012 report [available at https://www.rspb.org.uk/Images/illegal_killing_of_BoPs_in_scotland_tcm9-358482.pdf] last accessed 05/03/2014

2. D. Dick, Wildlife Crime - the making of an investigations officer, Glasgow: Whittles Publishing Ltd., 2012

3. T. Newburn, T. Williamson, A. Wirght, Handbook of criminal investigation, Willan Publishing Ltd., Devon, 2007

4. S. Bleay, Still making a mark? Fingerprints in the 21 st century, Science \& Justice, 2014, $54(1), 1-2$

5. G. Wilgus, Latent Print Recovery from Human Skin, Journal of Forensic Identification 52 (2) (2002) 133-135

6. W.C. Sampson, K.L. Sampson, Recovery of Latent Print from Human Skin, Journal of Forensic Identification 55 (3) (2007) 362-385

7. M. Trapecar, J. Balazic, Fingerprint recovery from human skin surfaces, Science \& Justice 47 (3) (2007) 136-140

8. G. Singh, G.S. Sodhi, O.P. Jasuja, Detection of latent fingerprints on fruits and vegetables, Journal of Forensic Identification 56 (3) (2006) 374-381

9. M. Trapecar, M.K. Vinkovic, Techniques for fingerprint recovery on vegetable and fruit surfaces used in Slovenia - a preliminary study, Science \& Justice 48 (4) (2008) 192195

10. S. Ferguson, L. Nicholson, K.J. Farrugia, D. Bremner, D. Gentles, A Preliminary Investigation into the Acquisition of Fingerprints on Food, Science \& Justice 53 (1) (2013) 67-72

11. J. Fraser, K. Sturrock, P. Deacon, S. Bleay, D. Bremner, Visualisation of Fingermarks and Grab Impressions on Fabrics, Part 1: Gold/Zinc Vacuum Metal Deposition, Forensic Science International 208 (1-3) (2011) 74-78.

12. J. Otis, A. Downing, Development of latent fingermark impressions on deer antlers, Journal of Forensic Identification 44 (1) (1994) 9-14. 
13. Czarnecki, E. Development of prints on antlers and horns, Journal of Forensic Identification 52 (4) (2002) 433-437

14. Eveleigh, G. Development of latent fingermarks on reptile skin, Journal of Forensic Identification 59 (3) (2009) 285-296

15. J.E. Huffman, J.R. Wallace, Wildlife Forensics: Methods and Applications (Developments in Forensic Science), Wiley-Blackwell, Oxford, 2011

16. A. Linacre, S. Tobe, Wildlife DNA Analysis: Applications in Forensic Science (Essential Forensic Science), Wiley-Blackwell, Oxford, 2013

17. J.E. Cooper, M.E. Cooper, Wildlife Forensic Investigation: Principles and Practice, CRC Press, Florida, 2013

18. Sears, V.G.; Bleay, S.M.; Bandey, H.L.; Bowman, V.J. A methodology for fingermark research. Sci \& Justice, 2012, 52 (3) 145-160.

19. Bowman, V., Ed. Manual of Fingerprint Development Techniques, $2^{\text {nd }}$ ed. $3^{\text {rd }}$ rev.; Home Office, Police Scientific Development Branch: Sandridge, U.K., 2009.

20. Liu, Y., Chen, X., \& Xin, J. H. (2008). Hydrophobic duck feathers and their simulation on textile substrates for water repellent treatment. Bioinspiration \& Biomimetics, 3(4), 46007.

21. Rahn H, Paganelli CV, Ar A. Pores and gas exchange of avian eggs: a review. J Exp Zool Suppl. 1987;1:165-72. 